\title{
Radiography student comparison performing lumbar and thoracic spine imaging
}

\author{
Rebeka Viltužnik ${ }^{1,2}$, Nejc Mekiš²*
}

'Jožef Stefan Institute, Ljubljana, Slovenia, ²Department of Medical Imaging and Radiotherapy, Faculty of Health Sciences, University of Ljubljana, Ljubljana, Slovenia

\begin{abstract}
Introduction: General radiography is a common imaging technique and X-ray examinations of the thoracic and lumbar spine are among the most frequent procedures undertaken. The aim of this research was to investigate the success rate, dose-area product (DAP), and effective dose values of $1^{\text {st }}$ and $2^{\text {nd }}$ cycle radiographer students performing $X$-ray imaging of the thoracic and lumbar spine using a phantom.

Methods: The students were divided into four groups according to the year of study $\left(1^{\text {st }}, 2^{\text {nd }}\right.$, and $3^{\text {rd }}$ years of $1^{\text {st }}$ cycle degree, and all $2^{\text {nd }}$ cycle degree students). They were asked to perform imaging of thoracic and lumbar spine on the phantom in both anteroposterior and lateral projections where IQ and DAP measurements were collated. The study was blind, so they did not know about the purpose of the study.

Results: First, we have inspected the acceptability rate of the images performed. The highest success rate of performing an optimal image was discovered with the $2^{\text {nd }}$ cycle degree students where the $1^{\text {st }}$ year students had the most difficulties there. In the second part, DAP and effective dose values were compared, only for the acceptable images in which case the $1^{\text {st }}$ and $2^{\text {nd }}$ years, students of the $1^{\text {st }}$ cycle degree were most successful.

Conclusion: Based on that, we can conclude, that the $2^{\text {nd }}$ cycle degree students had the lowest rejection rate regarding the optimal image quality, which was the price of using a larger primary X-ray field which leads to higher dose values.
\end{abstract}

Keywords: Radiography; students; student comparison; radiation dose

\section{INTRODUCTION}

Back pain is one of the most common causes why individuals seek medical help when it comes to musculoskeletal system. The pain usually originates from the lumbar section of the spine and $85 \%$ of the population experiences this symptom at least

\footnotetext{
*Corresponding author: Nejc Mekiš, Department of Medical Imaging and Radiotherapy, Faculty of Health Sciences, University of Ljubljana, Ljubljana, Slovenia. E-mail: nejc.mekis@zf.uni-lj.si
}

Submitted: 23 October 2020/Accepted: 03 December 2020 once in their lifetime. When it comes to medical evaluation of back pain, doctors usually choose medical imaging as one of the steps in seeking the cause of the pain (1).

General radiography is the simplest and cheapest medical imaging modality, where we can acquire a lot of important medical information, if the imaging is done correctly (2). According to the European Commission (EC) report, general radiography is the most commonly used medical imaging technique, but contributes only $17 \%$ of collective dose. The biggest contributors to the collective dose are CT scans, which make $40 \%$ of the collective dose. 
Chest X-rays are most frequent in conventional radiography, followed by the hip and pelvis X-rays and X-rays of the spine, abdomen, and mammography. Although lumbar spine X-rays are the $3^{\text {rd }}$ when it comes to the frequency, they have the highest dose in conventional radiography $(3,4)$.

Using radiation in healthcare is a very delicate process, since improper use of radiation can have serious consequences. The first step in approval is justification, where the person in charge must decide, if the benefits of the radiation usage outweigh the risks. Next step in this process is the optimization of the radiation technique, which means, that we get to ensure acceptable image quality for the given indication with the least possible dose (5). There is a lot of factors in conventional radiography that can be optimized, for example, exposure time, automatic exposure control (AEC) usage, shielding, diagnostic reference level (DRL), and field collimation, where a smaller field means a lower dose on the patient, but the field still needs to be big enough to get all the required information. If the field is too big, the ALARA principle is not followed and the image quality worsens, since more scatter is produced (6).

Radiography study program is divided into undergraduate cycle degree, which lasts 3 years, and postgraduate $\left(2^{\text {nd }}\right.$ cycle $)$ degree, which lasts 2 years. In the $1^{\text {st }}$ year of the undergraduate program, students get to know the physics of X-rays and protocols for conventional radiography as well as radiation protection basics. They upgrade their knowledge of general radiography throughout the next 2 years with new knowledge in computed tomography, magnetic resonance imaging, radiation physics and advanced radiation protection, nuclear medicine, and radiotherapy. All this radiography fields are explained in more depth in the postgraduate program which is optional.

Imaging protocols are specified and standardized methods to present desirable parts of the patient in a way that radiologists can make a diagnosis from the acquired image. When it comes to skeletal imaging, two perpendicular images are usually made, the anteroposterior (AP) view and the lateral view. The radiography students at our faculty are familiar with protocols from the work of Medič and Mekiš (7). The protocols include patient positioning, central ray placement and collimation, and exposures.
Technical requirements are all steps of the protocol that does not include patient positioning and collimation. For thoracic spine in both standard views, the focal point should be equal or $<1.3 \mathrm{~mm}$, the filtration should be $3 \mathrm{~mm}$ aluminum equivalent or more, the grid $r=10$ with 40 lamellas $/ \mathrm{cm}$, source-to-image receptor distance $115 \mathrm{~cm}$, tube voltage between $75 \mathrm{kV}$ and $85 \mathrm{kV}$ with the central AEC chamber selected, and exposition time $<200$ ms. Examination table or wall stand can be used, with the table being more common. Lumbar spine $\mathrm{X}$-rays demand similar technical requirements, except the tube voltage should be between $80 \mathrm{kV}$ and $90 \mathrm{kV}$ and the exposition time should be $<400$ $\mathrm{ms}$ in the AP view and $<1000 \mathrm{~ms}$ in the lateral view $(7,8)$.

The effect of radiation can be expressed through different dose units. The most basic one is absorbed dose, which tells us how much energy the ionizing radiation has deposited within the object (7). From this unit, we can calculate the dose area product (DAP) and according to Public Health England (9) the DRL for DAP in thoracic spine $\mathrm{X}$-ray is $100 \mu \mathrm{Gym}^{2}$ for the AP view and $150 \mu \mathrm{Gym}^{2}$ for the lateral view. According to Pažanin (10), the DAP value for AP view of the thoracic spine is $61.18 \pm 31.49 \mu \mathrm{Gym}^{2}$ and $61.53 \pm 43.31 \mu \mathrm{Gym}^{2}$, if the collimation is used correctly. For the lumbar spine, the EC (3) published that the DAP values range between $150 \mu \mathrm{Gym}^{2}$ and $1000 \mu \mathrm{Gym}^{2}$ with the $\mathrm{AP}$ view and between $275 \mu \mathrm{Gym}^{2}$ and 800 $\mu \mathrm{Gym}^{2}$ in the lateral view. Šalić and Vodopivec (11) found out in their research, where they took X-rays of the lumbar spine on the RS-113TS phantom that simulates pelvis and lumbar spine of the patient with $175 \mathrm{~cm}$ and $74 \mathrm{~kg}$, that the DAP value is $52.2 \mu \mathrm{Gym}^{2}$ for the AP and $119.6 \mu \mathrm{Gym}^{2}$ for the lateral view, if the collimation is optimal. They used constant exposure parameters of $75 \mathrm{kV}$ and $40 \mathrm{mAs}$ for the AP view and $85 \mathrm{kV}$ and $80 \mathrm{mAs}$ for the lateral view. According to their study it is evident, that the phantom measurements were lower than suggested DRL values for DAP. Equivalent dose can be calculated from DAP, but additionally, it also takes into account the biological effect of the type of ionizing radiation used. From that, effective dose can be derived, which also considers organ sensitivity to ionizing radiation (7). 
The purpose of this study is to show, if there are significant differences in the frequency of technically useful images, field collimation, and doses in technically useful images, between students in different study years of radiography program.

\section{METHODS}

First, descriptive method was used, where domestic and foreign literature was read, to determine the specifics and the theoretical base of this study.

We continued with the experiment, where X-rays were taken by 124 students, who were divided into four groups $-1^{\text {st }}$ year $(n=39), 2^{\text {nd }}$ year $(n=30), 3^{\text {rd }}$ year $(n=30)$, and postgraduates $(n=25)$. Before the study, a faculty approval was granted and an inform consent was obtained from each participant (student). Each individual student took $4 \mathrm{X}$-ray images using PBU 60 phantom (Kyoto Kagaku co., LTD, Japan) that simulates the patient with height of $165 \mathrm{~cm}$ and weight of $50 \mathrm{~kg}$, where they did lumbar and thoracic spine images in standard projections (AP and lateral). Central AEC chamber was used with the tube voltage of $75 \mathrm{kV}$ for thoracic spine imaging and for the lumbar spine $81 \mathrm{kV}$ and $75 \mathrm{kV}$ for the AP and the lateral view, respectively. With each exposure, we took down the primary field size and the DAP value. Next all images classified into one of the two groups - technically useful image or technically non-useful image. All of the images were evaluated by an experienced radiographer. The conditions for a useful image were taken from Medič and Mekiš (7) and were the following:

- Thoracic spine AP view:

- All 12 thoracic vertebrae are shown

- Cervicothoracic and thoracolumbar junction

- All thoracic-rib joints are shown

- Thoracic spine lateral view:

- All 12 thoracic vertebrae are shown

- Cervicothoracic and thoracolumbar junction

- All spinous processes are shown

- Lumbar spine AP view:

- All five lumbar vertebrae are shown

- All transversal processes are shown

- Thoracolumbar and lumbosacral junction

- Whole SIJ is shown

- Lumbar spine lateral view:

- All five lumbar vertebrae are shown
- All spinous processes are shown

- Thoracolumbar and lumbosacral junction

All the other parameters of interest were compared only for the technically useful images.

Effective dose was calculated with the PCXMC 2.0 program (STUK, Radiation and Nuclear Safety Authority in Finland) accordingly.

The program IBM SPSS STATISTICS 20 (IBM corporation, USA) was used to see, if the statistical differences between students were significant. The type of the statistical test was based on the type of variable and the normality of distribution. For differences in frequencies of useful images, Chisquare test was used. All other parameters for useful images were first analyzed with Shapiro-Wilk test, to determine the normality of distribution. If the data distribution was normal $(p<0.05)$, we continued with one-way ANOVA and if the differences between study years were significant, post hoc Tuckey analysis was used. If the distribution was not normal $(p>0.05)$, we continued with Kruskal-Wallis and if the differences were significant, post hoc analysis with pair-comparison was made. The significance level for all tests was 0.05 .

\section{RESULTS}

We started with the statistical analysis of frequencies of technical useful images of thoracic spine, where Chi-square test has shown, that there are no statistically significant differences in frequencies of technical useful images between study years in both standard views. Postgraduate students had the highest success rate $(76.0 \%)$ in the AP view, while $1^{\text {st }}$ year students had the highest success rate $(76.9 \%)$ in the lateral view.

We continued with the analysis of technical useful images, where there were significant differences $(p=0.038)$ in field size within lateral projection of the thoracic spine. Nonparametric post hoc analysis showed, that the differences were significant between $3^{\text {rd }}$ year students and $1^{\text {st }}$ and $2^{\text {nd }}$ year students, where the $3^{\text {rd }}$ year students used significantly bigger fields. While differences in field size were significant in the lateral view of the thoracic spine, differences in DAP values were significant in the AP view $(p=0.001)$, where post hoc analysis showed, 
that postgraduate students had significantly higher values in comparison with $1^{\text {st }}$ and $2^{\text {nd }}$ year students, while $3^{\text {rd }}$ year students had significantly higher values only compared to the $1^{\text {st }}$ year students. The results for DAP values are shown in Figure 1. Because DAP value and effective dose are correlated, it was expected that the differences were also significant $(p$ $=0.016)$ in effective doses in the AP view, where post hoc comparison showed again, that postgraduate students had significantly higher values in comparison with $1^{\text {st }}$ and $2^{\text {nd }}$ year students, while $3^{\text {rd }}$ year students had significantly higher values only compared to the $1^{\text {st }}$ year students. These results are shown in Figure 2. With the analysis of the data for the lumbar spine, we started with frequency analysis as well, where significant differences $(p<0.001)$ were present in both standard views. In both cases, $1^{\text {st }}$ year students had the lowest success rate $(20.5 \%$ in the AP and $51.3 \%$ in the lateral view), while postgraduate students were the most successful $(76 \%$ in the AP and $100 \%$ in the lateral view). $2^{\text {nd }}$ and $3^{\text {rd }}$ year student's success rate was closer to the success rate of postgraduate students. Analysis of technically useful images showed that there were no significant differences in field size $(p=0.354$ in the AP view and $p=0.714$ in the lateral view), DAP values $(p=0.998$ in the $\mathrm{AP}$ view and $p=0.185$ in the lateral view), and effective doses $(p=0.915$ in the $\mathrm{AP}$ view and $p=0.146$ in the lateral view) between students. The results for DAP values are shown in Figure 3 and for effective dose in Figure 4.
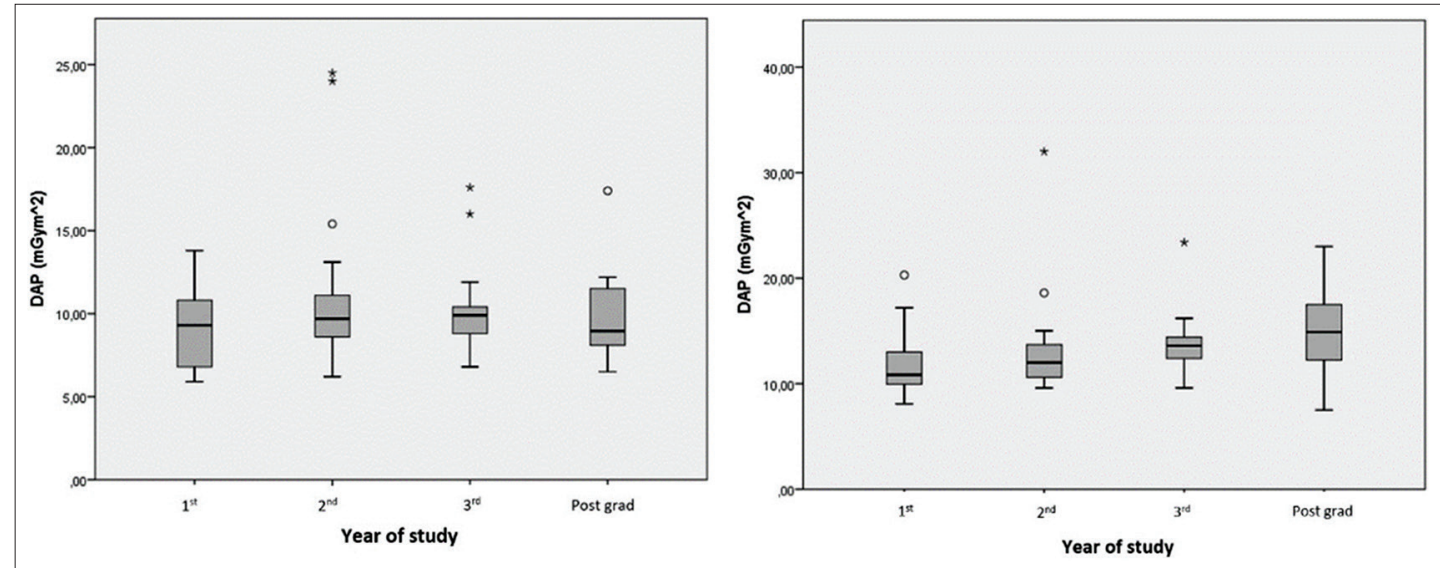

FIGURE 1. Dose area product comparison between study years for anteroposterior view (left) and lateral view (right) of useful images of the thoracic spine.
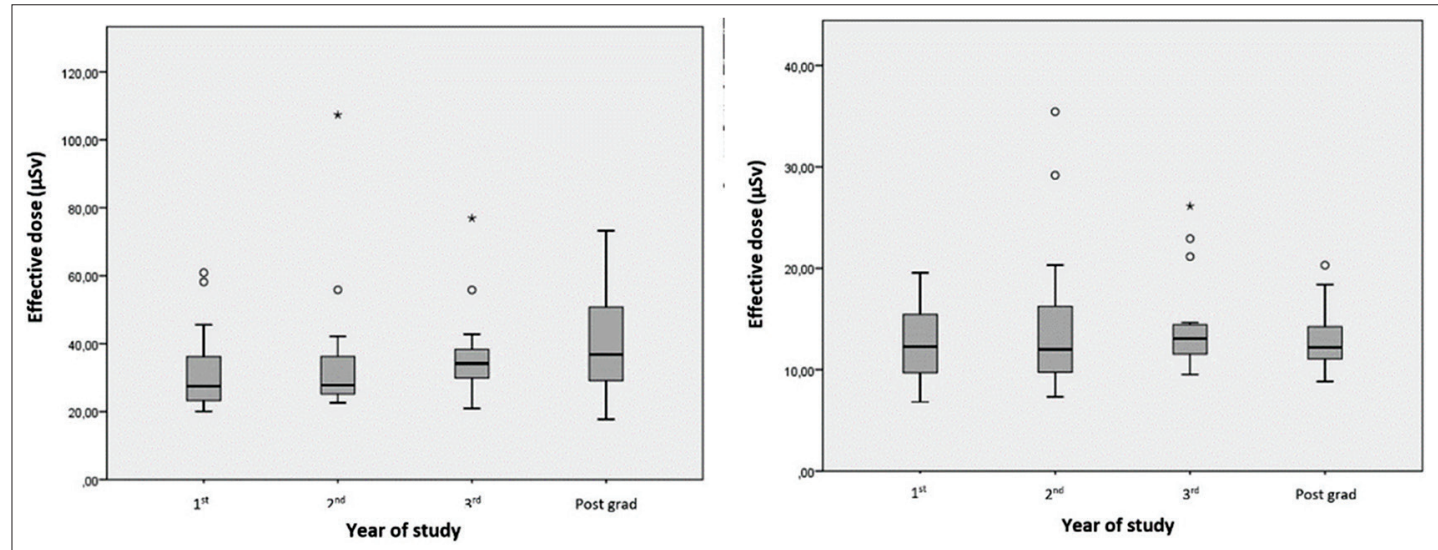

FIGURE 2. Effective dose comparison between study years for anteroposterior view (left) and lateral view (right) of useful images of the thoracic spine. 

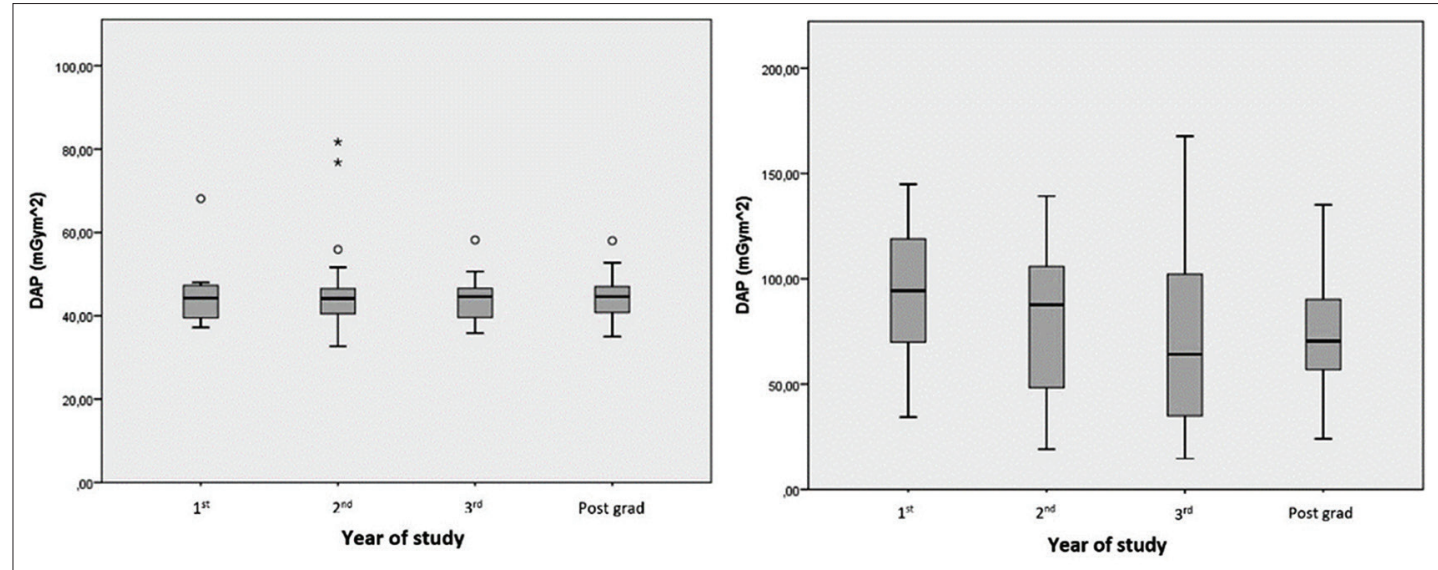

FIGURE 3. Dose area product comparison between study years for anteroposterior view (left) and lateral view (right) of useful images of the lumbar spine.

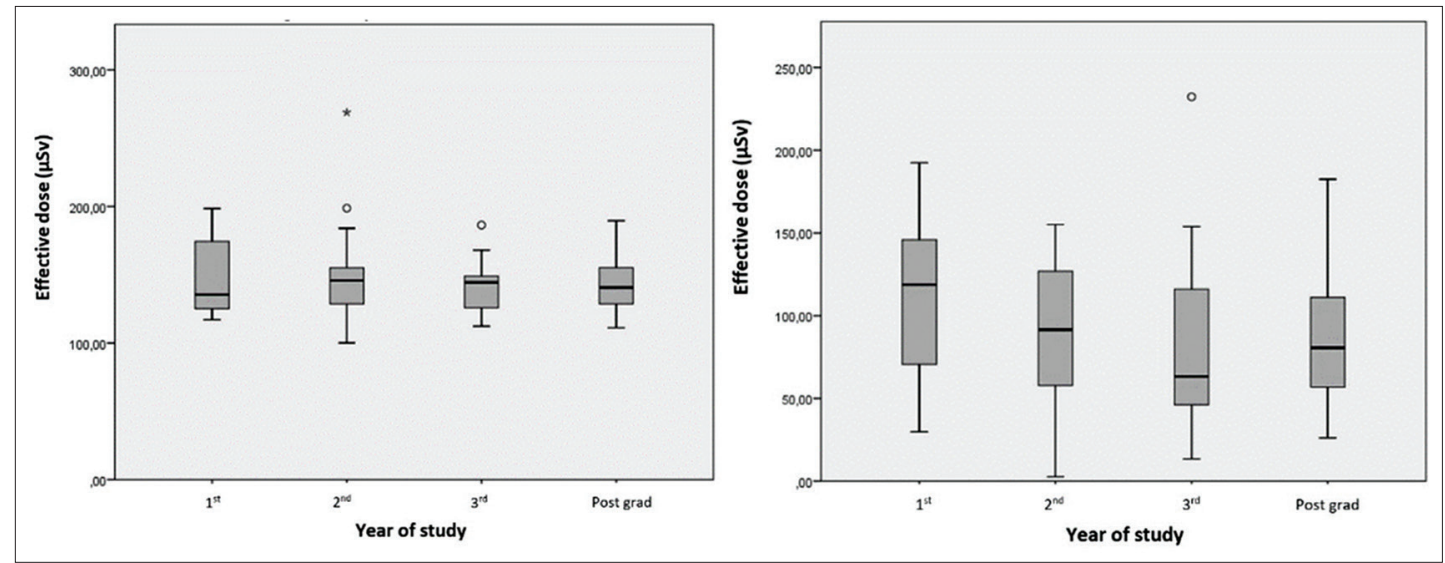

FIGURE 4. Effective dose comparison between study years for anteroposterior view (left) and lateral view (right) of useful images of the lumbar spine.

\section{DISCUSSION}

This experiment was made, to show, if there are significant differences between students of different study years of radiographic technology study program at the faculty where the study was performed and to compare these results to European standards and other literature.

Students had no significant problems with imaging of the thoracic spine in the AP view, where postgraduate students had greater field sizes than other groups, although the differences were not significant. The reason may be that these students have the most practical experiences out of all groups, where field height is usually not collimated, so there is as much information on the image as possible. The differences in dose values were significant, where $1^{\text {st }}$ year students had the lowest values. This can be due to the lack of practice, since they were centering the field according to the literature by Medic and Mekiš (7) and not according to the phantom. These students positioned the field higher (center of the sternum) than the other groups, where the phantom thickness was lower, resulting in lower doses. Compared to the literature, all student groups used larger field size than recommended, while the mean DAP values and mean effective doses, were much lower than European DRLs. This could have been because of the phantom that has the same absorption 
coefficient as a patient with height of $165 \mathrm{~cm}$ and mass of $50 \mathrm{~kg}$ (Body mass index [BMI] = 18.4). This means the phantom simulates a person with quite low BMI value, while the DRLs take into account the population average (ITM $=25-29)$. This can be applied to other results.

Students had some issues with acquiring all needed vertebrae in the lateral projection of the thoracic spine, where overall success was only $70.2 \%$. The DAP values and effective doses were lower compared to the AP view, which according to the literature should not be the case, because the phantom thickness is greater in the lateral view. This may have been caused by maintaining the middle ionizing chamber of AEC, which could have caused the exposure to end early. This also resulted in very bright images of the lateral view. Compared to the literature, student dose values were $90 \%$ lower than those suggested in the literature. Again, this can be due to the phantom and retaining the middle ionizing chamber.

Among all projections in this research, the students had the most difficulties with the AP view of the lumbar spine where overall success rate was less than half and the differences between groups were significant. $1^{\text {st }}$ year students had only $20.5 \%$ success rate, where they had problems with including both sacroiliac joints in the image, because they once again positioned and collimated accordingly to Medič, Mekiš (7) literature, while the phantom demanded a different positioning and/or collimation. The highest success rate was once again achieved by the postgraduate students, which can again be the result of having the most practice among all groups. The DAP and effective doses were once again much lower than in the literature. According to EC standards, the suggested values were between $150 \mu \mathrm{Gym}^{2}$ and $1000 \mu \mathrm{Gym}^{2}$, while average DAP values of all groups did not exceed $50 \mu \mathrm{Gym}^{2}$. The reason for low values may be the phantom. The suggested effective dose from the literature for this projection is $700 \mu \mathrm{Sv}$, while the highest average value of all groups is $152 \mu \mathrm{Sv}$.

The differences in success were also significant in the lateral view of the lumbar spine, where $1^{\text {st }}$ year student had the most problems once again. They had difficulties including all spinous processes needed in the image, because they positioned the field too anteriorly. Technically useful images of all groups, along with all needed anatomical features, also included two or more thoracic vertebrae in most cases, which means, that the students could have collimated the field more in the vertical direction. The DAP values and effective doses were once again much lower than the suggested values from the literature. For example, the effective doses were less than a third of the suggested values, where the effective dose should be $300 \mu \mathrm{Sv}$.

\section{CONCLUSION}

In this study, we cannot choose a group that exceeds all, where the success rate of postgraduate students was usually the highest, but the image size and consequently the doses were usually higher compared to other groups. Hence, although the potential image retake count was lower, the ALARA principle was not fully realized.

The results of this study could have been somewhat different, if all students from all years of study would participate in this study, but the participation was voluntary, so not all students decided to be a part of this study.

\section{ACKNOWLEDGMENTS}

We would like to thank all the students that took time and contributed to the study.

\section{REFERENCES}

1. Kert S. In: Predavanj Z, editor. Bolnik z Bolečino v Hrbtenici pri Izbranem Zdravniku. Maribor: Hrbtenica v Ortopediji; 2012. p. 55-63.

2. Rupreht M. In: Predavanj Z, editor. Slikovne Preiskave v Diagnostiki Hrbtenice. Maribor: Hrbtenica v Ortopediji; 2012. p. 97-104 [cited 2020 Oct 6]. Available from: http://www.ism-mb.si/files/Hrbtenica_2012.pdf.

3. European Union. Diagnostic Reference Levels in Thirty-six European Countries. Part 2/2. Radiation Protection No 180; 2015 [cited 2020 Oct 6]. Available from: https://www.ec.europa.eu/energy/sites/ener/files/documents/RP180 part2.pdf.

4. European Union. Diagnostic Reference Levels in Thirty-six European Countries. Part 1/2. Radiation Protection No. 180; 2015 [cited 2020 Oct 6]. Available from: https://www.ec.europa.eu/energy/sites/ener/files/documents/RP180.pdf.

5. Valentin J, editor. The 2007 Recommendations of the International Commission on Radiological Protection. Orlando: Elsevier, International Commission on Radiological Protection; 2007. p. 332.

https://doi.org/10.6028/nbs.hb.47.

6. European Commission. European Guidlines on Quality Criteria for Diagnostic Radiographic Images, EUR 16260 EN; 1996 [cited 2020 Oct 6]. Available 
from: https://www.sprmn.pt/pdf/EuropeanGuidelineseur16260.pdf.

7. Medič M, Mekiš N. Diagnostične Radiološke Metode: Skeletna Diagnostika: Učbenik za Študente Radiološke Tehnologije. Ljubljana: Zdravstvena Fakulteta; 2018. p. 478.

8. Busch HP. Image quality and dose management in digital radiography: A new paradigm for optimisation. Radiat Prot Dosimetry 2005;117(1-3):143-7 [cited 2020 Oct 6]. Available from: https://www.sorf.fi/doc/diamond_III.pdf. https://doi.org/10.1093/rpd/nci728.
9. Public Health England. National Diagnostic Reference Levels: 22 January 2016 to 14 November 2018; 2018.

10. Pažanin A. Vpliv Optimalnega Zaslanjanja na dozo lonizirajočega Sevanja pri Rentgenskem Slikanju Ledvene in Torakalne Hrbtenice v Splošni Diagnostiki. Master's Thesis/Paper; 2019.

11. Šalić P, Vodopivec T. Vpliv Zaslanjanja Polja na Dozno Obremenitev pri Radiografiji Ledvene Hrbtenice v Anteroposteriorni in Stranski Projekciji; 2017 [cited 2020 Oct 6]. Available from: https://www.repozitorij.uni-lj.si/ izpisgradiva . php?id=94581\&lang=slv. 